\title{
A CASE REPORT OF AMIODARONE INDUCED MYOPATHY IN A PATIENT OF VENTRICULAR ARRHYTHMIA
}

\author{
Rajat Mishra1 , Santhosh Kumar R. Jeevangi², Vardhamane S. H³, Prashant Dass ${ }^{4}$, Pradeep ${ }^{5}$
}

\section{HOW TO CITE THIS ARTICLE:}

Rajat Mishra, Santhosh Kumar R. Jeevangi, Vardhamane S. H, Prashant Dass, Pradeep. "A Case Report of Amiodarone Induced Myopathy in a Patient of Ventricular Arrhythmia". Journal of Evolution of Medical and Dental Sciences 2014; Vol. 3, Issue 47, September 25; Page: 11483-11486, DOI: 10.14260/jemds/2014/3504

ABSTRACT: Myopathies are disorders with structural changes or functional impairment of muscle. Voluntary muscle is subject to a range of hereditary and acquired disorders affecting either its structure, or the biochemical processes which convert the chemical energy derived from cell metabolism into mechanical energy in a controlled manner. These disorders present in a limited number of ways, most commonly a symmetrical weakness of the large, power-generating proximal muscles. Drug induced myopathy comes under acquired causes of myopathy. Here we shall be presenting a case of Amiodarone induced myopathy in a 40 years old male patient of ventricular arrhythmia. We shall also discuss the further management of this presentation.

KEYWORDS: Myopathies, Amiodarone, ventricular arrhythmia.

INTRODUCTION: Myopathies are neuromuscular disorders in which the primary symptom is muscle weakness due to dysfunction of muscle fibre. Other symptoms can be muscle cramps, stiffness and spasm. Myopathies are of two types:

- Inherited

- Acquired

Drug induced myopathy is an acquired type of myopathy. Some of the common drugs causing myopathies by different mechanisms are as follows:

- Direct Myotoxicity - Glucocorticoids, Statins, Colchicine, Zidovudine and antimalarials.

- Immunologically induced myopathy- D Penicillamine.

- Indirect muscle damage- Drug induced hypokalemia (Diuretics), hypothermia due to Cocaine, Neuroleptic malignant syndrome (Antipsychotics).

Amiodarone causing myopathy is rare. The exact mechanism by which it causes myopathy is still not very clear.

CASE REPORT: A 40 yrs old male patient came with complains of symmetrical muscle weakness of arms and legs along with difficulty in shaving and combing his hair. He also complained of difficulty in getting up from chair since past 8-10 days. The patient did not have any history of similar complains in the past nor he remembered any of his close family members with similar complains. However the patient gave a history of ventricular arrhythmia 3 months back for which he was on I.V Amiodarone for 5 days followed by oral Amiodarone $800 \mathrm{mg}$ for one month and then $400 \mathrm{mg}$ from last two months.

On examination no muscle tenderness or muscle wasting was present. His sensations and reflexes were normal. Apart from that all other systemic examination was normal. Routine blood, urine test and serum electrolytes were normal. 
No antinuclear antibodies were detected. Blood sugar was within normal range. ECG did not show any features of hypo or hyperkalemia. However, Creatinine Kinase was 1641IU/L (normal value: $55-170 \mathrm{IU} / \mathrm{L}$ this value range may vary from lab to lab).

Muscle biopsy showed mild atrophic changes. Electromyography was normal. MRI and Genetic testing was not done. His other tests Like Thyroid Function test (TFT), Liver Function Test (LFT) and Chest X ray were all within normal limits. However Slit Lamp examination showed corneal micro deposits. No relevant drug-drug interactions were identified to explain his myopathy.

Amiodarone was temporarily stopped and it was substituted by Sotalol at a dose of $80 \mathrm{mg}$ BD (class II antiarrhythmic drug with also class III actions) on consultation with Cardiologist. Apart from that L. Carnitine was prescribed once daily. His pulmonary functions were monitored once weekly. High protein diet was advised, along with physiotherapy.

He improved gradually within a month and his Creatinine Kinase level also came down (160IU/L). After 2 months of treatment with Sotalol we reintroduced Amiodarone, on consultation with the Cardiologist at a dose of $100 \mathrm{mg}$ BD. Just prior to reintroduction of Amiodarone, Creatinine Kinase was done and it was (110IU/L).Patient was followed weekly for a month and then biweekly for next 2 months. His Creatinine kinase level at the end of three months treatment with Amiodarone was (114IU/L). In between he was ask to come back immediately in case of any weakness.

\section{STRUCTURE:}

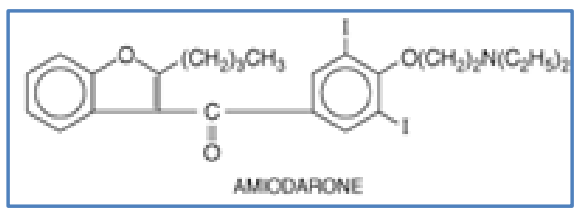

DISCUSSION: Amiodarone is an iodine containing highly lipophilic class III antiarrhythmic drug used in ventricular and supraventricular arrhythmias.[1] It is a multiple channel blocker, primarily a $\mathrm{K}^{+}$ channel blocker so prolong phase 3 Repolarisation.[2] Apart from $\mathrm{K}^{+}$channel blocker it is also a $\mathrm{Na}^{+}$ and $\mathrm{Ca}^{++}$channel blocker with beta blocking property.[2]

It is also used to maintain sinus rhythm in atrial fibrillation. ${ }^{[3]}$ It is commonly used antiarrhythmic drug because of high efficacy and low pro arrhythmic potential. ${ }^{[4]}$ Amiodarone is effective in a wide range of ventricular and supraventricular arrhythmia. Rapid termination of ventricular and supraventricular arrhythmia can be obtained with iv injection.

It is incompletely and slowly absorbed from GIT and action of the drug develops over several days or even weeks. It is metabolized in liver by CYP3A4. ${ }^{[5]}$ Plasma half-life is 3-8 weeks.[5] Grapefruit juice can inhibit amiodarone metabolism and leads to elevated amiodarone level in the blood.5]

Amiodarone can increase Digoxin and Warfarin level by reducing their renal clearance. It should not be used with beta blocker or calcium channel blockers as additive AV block can occur.

However it has side effects like hypotension, bradycardia only seen on rapid IV infusion.[2] Pulmonary fibrosis (most serious but rare if dose is kept below 200mg), photosensitization, blue skin discoloration, hypothyroidism or hyperthyroidism, peripheral neuropathy, corneal microdeposits, and peripheral neuropathy.[2]

Out of all these hypothyroidism, pulmonary fibrosis and peripheral neuropathy are said to be because of presence of iodide in their structure. ${ }^{[2]}$ Amiodarone induced myopathy is rare.[6] 
The management of drug induced myopathy is first stoppage of the drug and then it should be managed symptomatically [7].Here re-challenge with Amiodarone was done but at a lower dose $100 \mathrm{mg}$ BD. However it must be said that the dose of Amiodarone prescribed as maintenance therapy for this patient initially (400mg) was high so he was a likely candidate for adverse drug reaction.

According to WHO-UMC and Naranjo's causality assessment it came under probable/likely cause. According to Adapted Hartwig severity scale it had a score of 4 which was moderate in nature. According to Schumock and Thornton preventability and assessment criteria showed it under definitely preventable category.

Amiodarone induced myopathy has been defined in few cases. The time of appearance of this side effect in the present case was almost similar to that reported in literature between 12-14 weeks. ${ }^{[8]}$ Moreover myopathy regressed after discontinuing the treatment. ${ }^{[8,9]}$ However there can also be a dose related mechanism as this patient was on high dose (400mg).

CONCLUSION: Clinicians should be aware of common drugs known to cause myopathy. Early recognition and drug cessation or even dose reduction are essential in management of patients with drug induced myopathy.

Although the clinical and diagnostic features may vary depending upon the causative agent, they are reversible after discontinuation or even reduction in dose.

Risk factors associated with drug induced myopathy are hepatic and renal insufficiency, enzyme inhibition and concomitant use of myotoxic drugs.

There is a high incidence of proximal myopathy in diabetic patients so Amiodarone should be used with caution especially in those patients who are diabetic for many years. The moment problem is identified the drug should be discontinued or even dose should be decreased (in case of high dose) and substituted with some other antiarrhythmic drug.

\section{REFERENCES:}

1. Goldschlager N, Epstein AE, Naccarelli G, Olshansky B, Singh B. Practical Guidelines Subcommittee North American Society of Pacing and Eletrophysiology 2000;160:1741-8.

2. Tripathi KD. Essentials of Medical Pharmacology; $7^{\text {th }}$ edition: 526-38.

3. Montvale NJ Physician's desk reference 56 th ed Medical Economics 2002

4. Khan MH, Oral class III anti arrhythmics; what is new? Current opinion in Cardiology 2004;19 (1): 2189-96

5. Libersa C C, Brique SA, Motte KB, Caron JF. Dramatic inhibition of amiodarone metabolism induced by grape juice. Br J clin Pharmacol 2000; 49: 373-78.

6. Siddoway L A, Amiodarone guidelines for use and monitoring. America Family Physician. 2003; Dec 1; 68 (1): 2189-96

7. JanL. DE Bleecker. How to approach the patient with muscle symptoms in general neurological practice. Acta Neurol Belgium2005;105:18-22

8. Khalil -UR-Rehman, Farooq Nazir, Talaha F. Nazir. Amiodarone induced proximal myopathy. Pakistan heart journal 1996; 29 (3-4): 40-42

9. Pulipaka U, Lacomis D, Omalu BAmiodarone-induced neuromyopathy: three cases and a review of the literature. J Clin Neuromuscul Dis. 2002 Mar; 3 (3): 97-105. 


\section{CASE REPORT}

\section{AUTHORS:}

1. Rajat Mishra

2. Santhosh Kumar R. Jeevangi

3. Vardhamane S. H.

4. Prashant Dass

5. Pradeep

\section{PARTICULARS OF CONTRIBUTORS:}

1. Post Graduate Resident, Department of Pharmacology, Mahadevappa Rampure Medical College, Gulbarga.

2. Associate Professor, Department of Pharmacology, Mahadevappa Rampure Medical College, Gulbarga.

3. Professor and HOD, Department of Pharmacology, Mahadevappa Rampure Medical College, Gulbarga.

4. Post Graduate Resident, Department of Pharmacology, Mahadevappa Rampure Medical College, Gulbarga.
5. Post Graduate Resident, Department of Pharmacology, Mahadevappa Rampure Medical College, Gulbarga.

\section{NAME ADDRESS EMAIL ID OF THE CORRESPONDING AUTHOR:}

Dr. Rajat Mishra,

Post Graduate Resident,

Department of Pharmacology,

Mahadevappa Rampure Medical College,

Gulbarga-585105, Karnataka.

Email: mishra.rajat13@gmail.com

Date of Submission: 11/09/2014.

Date of Peer Review: 12/09/2014.

Date of Acceptance: 18/09/2014.

Date of Publishing: 25/09/2014. 